\title{
REAPROVEITAMENTO DO RESÍDUO DA INDÚSTRIA DE CARNAÚBA NO SUBSTRATO PARA PRODUÇÃO DE MUDAS DE MELANCIA
}

\author{
Alcilane Arnaldo Silva ${ }^{1}$, Leonardo Pereira da Silva Brito ${ }^{2}$, Márkilla Zunete Beckmann
} Cavalcante $^{3}$, José Alves Pessoa Neto ${ }^{1 *}$, Ítalo Herbert Lucena Cavalcante ${ }^{3}$

\footnotetext{
${ }^{1}$ Mestrando(a) em Agronomia pela Universidade Federal do Piauí - UFPI, Campus Profa. Cinobelina Elvas, Bom Jesus, PI, Brasil. *E-mail: josealvespn@ @otmail.com

${ }^{2}$ Doutorando em Agronomia pela Universidade Federal de Lavras - UFLA, Lavras, MG, Brasil

${ }^{3}$ Professor(a) Dr(a). do Curso de Engenharia Agronômica, Universidade Federal do Vale do São Francisco UNIVASF, Petrolina, PE, Brasil
}

RESUMO: Os produtores de mudas de hortaliças estão sempre ávidos por novas tecnologias, especialmente quando se trata do insumo substrato para plantas. Neste sentido, objetivou-se avaliar o desenvolvimento de mudas de melancia cultivar Crimson Sweet, produzidas em diferentes proporções de resíduo de carnaúba para composição de substratos. O experimento foi conduzido em delineamento experimental inteiramente casualizado com cinco tratamentos com diferentes proporções de resíduo de carnaúba com casca de arroz (RCCA) e resíduo de carnaúba em pó (RCP): 1) $100 \%$ RCCA; 2) $75 \%$ RCCA + $25 \%$ RCP; 3) $50 \%$ RCCA + 50 \% RCP; 4) $25 \%$ RCCA + 75 \% RCP; e 5) $100 \%$ RCP com quatro repetições de 64 plântulas cada. Há influência do uso resíduo de cera de carnaúba como componente de substrato na formação de mudas de melancia cv. Crimson Sweet. O substrato 100\% RCCA pode ser usado na produção de mudas de melancia de qualidade.

Palavras-chave: Citrullus lanatus. Copernicia prunifera. Resíduos orgânicos.

\section{REUSE OF CARNAUBA INDUSTRY RESIDUE AS SUBSTRATE FOR PRODUCTION OF WATERMELON SEEDLINGS}

\begin{abstract}
Producers of vegetable seedlings are always avid for new technologies, especially when it comes to the input substrate for plants. In this sense, the objective was to evaluate the development of watermelon seedlings cultivar Crimson Sweet, produced in different carnauba residue ratios for substrate composition. The experiment was conducted in a completely randomized experimental design with five treatments consisting of different proportions of carnauba residue with rice husk (RCCA) and carnauba powder residue (RCP): ) $100 \% \mathrm{RCCA}$; $275 \% \mathrm{RCCA}+25 \% \mathrm{RCP}$; 3$) 50 \% \mathrm{RCCA}+50 \% \mathrm{RCP}$;) $25 \% \mathrm{RCCA}$ $+75 \%$ RCP and 5) $100 \%$ RCP with four replicates and 64 seedlings each. There is influence of the use of carnauba residue as a substrate component in the formation of watermelon seedlings cv. Crimson Sweet. The substrate composed of 100\% RCCA can be used for the production of quality watermelon seedlings.
\end{abstract}

Key words: Citrullus lanatus. Copernicia prunifera. Organic waste.

Cultura Agronômica, Ilha Solteira, v.26, n.1, p.10-20, 2017 


\section{INTRODUÇÃO}

A melancieira (Citrullus lanatus) tem sido cultivada em quase todos os estados brasileiros, especialmente aqueles da região Nordeste, onde mais de $60 \%$ da melancia nacional é produzida (IBGE, 2015).

Muitos produtores brasileiros ainda adotam o sistema de semeadura direta no solo, uma prática que, embora reduza o custo de produção inicial, vem sendo substituída pela produção de mudas devido ao elevado valor de sementes híbridas, além de promover melhor controle de nutrição e fitossanidade, tornando possível a seleção de plantas mais vigorosas e consequentemente, garantindo a homogeneidade do cultivo (MATOS et al., 2012).

Nesse sentido, a formulação do substrato tem sido estudada com objetivo de obter composições que ofereçam uniformidade, baixa densidade, elevada capacidade de troca catiônica e capacidade de retenção de água, além de boa aeração e drenagem, proporcionando condições ideais para o crescimento e desenvolvimento de mudas (ALBANO et al., 2014). Dentre os produtos com potencial de uso como substrato destaca-se resíduo de carnaúba (Copernicia prunifera), subproduto da produção de cera, cujo efeito na produção de mudas ainda é pouco abordado na literatura científica, mas há resultados satisfatórios para mudas de helicônias (CAVALCANTE et al., 2011), mamoeiro (ALBANO et al., 2014), tomateiro (SILVA-JÚNIOR et al., 2014), jatobá (LUSTOSA FILHO et al., 2015) e tamboril (SOUSA et al., 2016).

Para a cultura da melancia, não há registros na literatura de produção de mudas com substratos que contenha bagaço de carnaúba, entretanto, ocorre com outros resíduos na composição de substratos, a exemplo de Lopes et al. (2013) que avaliaram diferentes substratos comerciais na produção de mudas e observaram que a fibra de coco proporcionou maior produção de massa seca, maior altura de planta e comprimento de raiz; e, Souza et al. (2014) que concluíram que o esterco ovino na composição de substratos orgânicos constituise em uma alternativa viável para a produção de mudas de melancia.

Nesse sentido, o presente trabalho foi desenvolvido com o objetivo de avaliar as características agronômicas de mudas de melancia produzidas em substrato contendo resíduo da indústria de cera de carnaúba.

\section{MATERIAL E MÉTODOS}

O experimento foi conduzido em ambiente protegido no Setor de Horticultura do Campus Prof ${ }^{a}$. Cinobelina Elvas da Universidade Federal do Piauí, situado no município de Bom Jesus, Piauí, localizado às coordenadas geográficas $09^{\circ} 04^{\prime 2} 28^{\prime \prime} \mathrm{S}, 44^{\circ} 21^{\prime} 31^{\prime \prime} \mathrm{O}$ e, altitude média de $277,0 \mathrm{~m}$.

O ambiente protegido usado foi do tipo "capela", com as seguintes dimensões internas: 5,0 $\mathrm{m}$ de comprimento e 3,0 $\mathrm{m}$ de largura (área total de $15,0 \mathrm{~m}^{2}$ ) e pé direito de 3,0 m, orientado no sentido leste-oeste, protegido com tela de polipropileno com $50 \%$ de 
sombreamento, sobre todos os lados da estrutura metálica (partes superior e laterais) e, coberto com polietileno de baixa densidade, com $150 \mu \mathrm{m}$ de espessura.

As mudas foram conduzidas em bandejas de poliestireno expandido (isopor), com 128 células dispostas em duas bancadas perpendiculares com dimensões de 4,9 $\mathrm{m}$ de comprimento por 1,0 m de largura e 1,0 m de altura. Foram utilizadas sementes de melancia cv. Crimson Sweet (Topseed ${ }^{\circledR}$, Brasil). Após o preenchimento das bandejas procedeu-se a semeadura colocando-se duas sementes por célula, sendo realizado o desbaste aos 12 dias após a semeadura, deixando-se uma planta por célula.
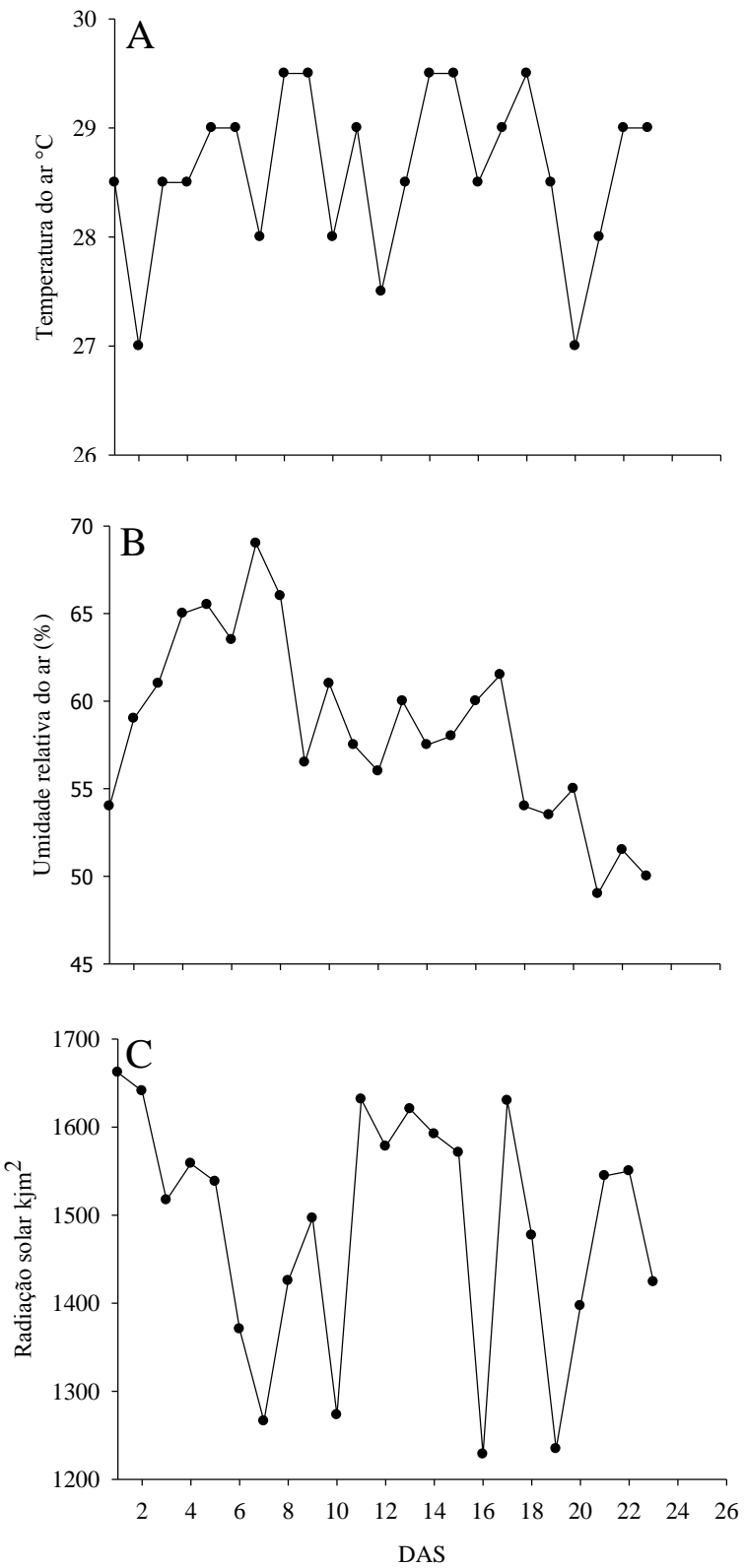

Figura 1. Temperatura do ar (A), umidade relativa do ar (B) e radiação solar (C) durante 23 dias após a semeadura. 
Durante a execução do experimento até o $23^{\circ}$ dia após a semeadura (DAS) foram monitoradas diariamente a temperatura do ar, a umidade relativa do ar e a radiação solar, obtidos a partir dos registros em estação climatológica localizada no setor de Horticultura (Figura 1).

A adubação das mudas foi realizada via foliar aplicando-se, com auxílio de um pulverizador costal, oito litros de calda de fertilizante foliar organomineral classe B (Vitan ${ }^{\circledR}$ Sudoeste Agropecus Ind. Com. Ltda, Brasil), na dosagem 100 mL. $100 \mathrm{~L}^{-1}$. As adubações foram repetidas a cada sete dias até o final do experimento conforme recomendações do fabricante, totalizando quatro aplicações. $\mathrm{O}$ adubo foliar organomineral apresenta em sua composição macro e micronutrientes, com as seguintes garantias, em $\mathrm{g} \mathrm{L}^{-1}: \mathrm{N}-87 ; \mathrm{P}_{2} \mathrm{O}_{5^{-}}$116; $\mathrm{K}_{2} \mathrm{O}$ - 116; Ca - 14,5; S - 34,8; Mg - 7,2; B - 8,7; Cu - 2,9; Mn - 7,2; Mo - 2,9 e Zn - 14,5. As mudas foram irrigadas duas vezes por dia em intervalos de oito horas utilizando um pulverizador costal manual.

O delineamento experimental adotado foi inteiramente casualizado com cinco tratamentos e quatro repetições de 64 plantas cada. Os materiais usados para formulação dos substratos foram resíduo de carnaúba (Copernicia prunifera) com casca de arroz (Oriza sativa) (RCCA) e resíduo de carnaúba em pó (RCP), obtendo-se as seguintes composições: 1) $100 \% \mathrm{RCCA}$; 2) $75 \% \mathrm{RCCA}+25 \% \mathrm{RCP}$; 3) $50 \% \mathrm{RCCA}+50 \% \mathrm{RCP}$; $) 25 \% \mathrm{RCCA}$ $+75 \%$ RCP; e 5) $100 \%$ RCP.

Os resíduos RCCA e RCP foram provenientes de usinas de transformação, pelo processo industrial, do pó de carnaúba em cera. Os materiais utilizados como substratos foram esterilizados em autoclave vertical com temperatura de $120^{\circ} \mathrm{C}$, por um período de uma hora e caracterizados física e quimicamente, conforme se pode observar na Tabela 1.

Tabela 1. Caracterização química e física dos resíduos industriais da cera de carnaúba usados na composição dos substratos

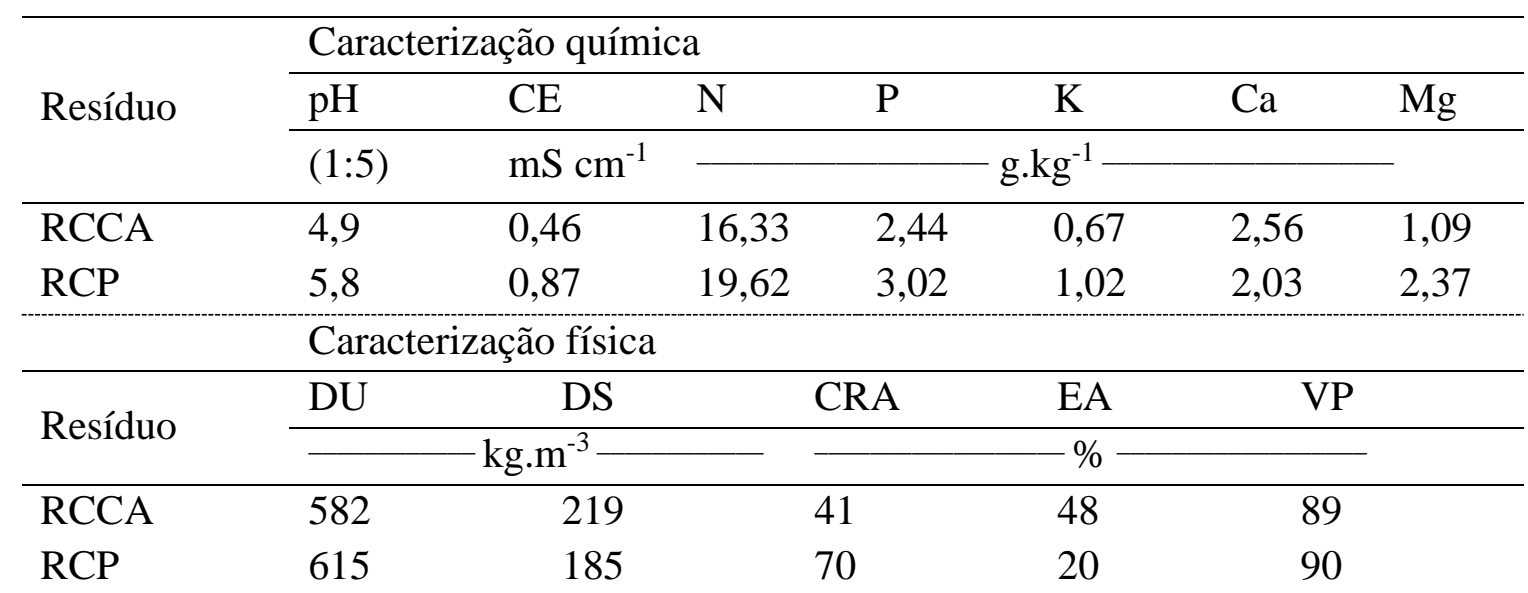

RCCA: resíduo da carnaúba + casca de arroz; RCP: resíduo da carnaúba em pó; CE = condutividade elétrica; DU: Densidade úmida; DS: densidade seca; CRA: capacidade de retenção de água; EA: espaço de aeração; VP: volume dos poros.

Cultura Agronômica, Ilha Solteira, v.26, n.1, p.10-20, 2017 
$\mathrm{Na}$ caracterização química foram analisados pH e condutividade elétrica (CE), de acordo com MAPA (2007) e os teores totais dos macronutrientes (N, P, K, Ca e Mg), em extrato nítrico-perclórico (MALAVOLTA et al., 1997). Na caracterização física foram realizadas análises de densidade úmida (DU) e densidade seca (DS) segundo procedimento de MAPA (2007) e, capacidade de retenção de água (CRA), espaço de aeração (EA) e volume dos poros (VP), determinados conforme os procedimentos descritos por Cavalcante (2007).

A partir do quinto dia após a semeadura foram realizadas leituras diárias, registrandose a emergência (E) de plântulas para determinação do índice de velocidade de emergência (IVE) de acordo com Maguire (1962). Consideraram-se plântulas emergidas aquelas cujos cotilédones permaneciam visíveis sobre o substrato.

Aos 23 dias após a semeadura quando as plantas apresentavam pelo menos duas folhas definitivas, foram retiradas 10 plântulas por parcela, separadas em parte aérea e sistema radicular e determinadas as seguintes variáveis: a) altura de planta $(\mathrm{cm})$, determinada com régua milimetrada, a partir do coleto até a gema apical; b) área foliar $\left(\mathrm{cm}^{2}\right)$, pelo uso do medidor automático de área foliar de bancada modelo LI-3100C (Li-Cor, Biosciences ${ }^{\circledR}$, USA); c) diâmetro do caule (mm), medido na base do coleto utilizando-se um paquímetro digital (Digimess ${ }^{\circledR}$ Brasil) com precisão de $0,01 \mathrm{~mm}$; d) comprimento da maior raiz $(\mathrm{cm})$, medida com régua milimetrada, a partir do coleto até a extremidade da maior raiz; e) volume de raiz $\left(\mathrm{cm}^{3}\right)$ realizado seguindo metodologia descrita por Basso (1999); f) massa seca da parte aérea e da raiz (expressas em g planta $^{-1}$ ), pesada em balança com precisão de $0,001 \mathrm{~g}$ (Bioprecisa ${ }^{\circledR}$, Brasil). Para determinação da massa seca, o material vegetal foi colocado em estufa com circulação forçada de ar à temperatura de $65^{\circ} \mathrm{C}$ até atingir massa constante; h) estabilidade de torrão, realizada considerando sua coesão ao retirar a planta do recipiente considerando uma escala de notas adaptada de Gruszynski (2002) em que $1=$ mais de $50 \%$ do torrão ficou retido no recipiente; $2=0$ torrão se destacou do recipiente, mas não permaneceu coeso e 3 = todo o torrão foi destacado do recipiente e mais de $90 \%$ dele permaneceu coeso.

Os dados foram submetidos à análise de variância, e os tratamentos comparados entre si pelo teste de Tukey, através do programa computacional Assistat.

\section{RESULTADOS E DISCUSSÃO}

A porcentagem de plântulas emergidas não foi influenciada pelos substratos com concentrações de resíduo de carnaúba (Tabela 2), o que pode estar relacionado à alta porosidade dos substratos resíduo de carnaúba + casca de arroz (RCCA) e resíduo de carnaúba em pó (RCP) (Tabela 1), utilizado para a composição dos tratamentos. Essa característica presente no substrato, sob as condições experimentais adequadas, permite a infiltração de água no teor adequado e favorece a emergência das plântulas (GONÇALVES; BENEDETTI, 2004). A ausência de efeito estatístico para a emergência de plântulas foi também registrada por Oliveira et al. (2006), avaliando substratos orgânicos na produção de mudas de berinjela,

Cultura Agronômica, Ilha Solteira, v.26, n.1, p.10-20, 2017 
embora os percentuais de emergência tenham sido semelhantes aos registrados por Souza et al. (2014), ao avaliarem a produção de mudas de cucurbitáceas utilizando esterco ovino na composição de substratos orgânicos.

Tabela 2. Emergência (\% E) e índice de velocidade de emergência (IVE) de plântulas de melancia cultivadas em substratos contendo resíduo da indústria de carnaúba

\begin{tabular}{lll}
\hline Causa de variação & $\% \mathrm{E}$ & IVE \\
\hline Substrato ("F") & $0,97^{\mathrm{ns}}$ & $7,87^{* *}$ \\
S1 & $99,41 \mathrm{a}$ & $134,61 \mathrm{a}$ \\
S2 & $99,41 \mathrm{a}$ & $127,53 \mathrm{a}$ \\
S3 & $99,61 \mathrm{a}$ & $131,10 \mathrm{a}$ \\
S4 & $98,63 \mathrm{a}$ & $122,64 \mathrm{ab}$ \\
S5 & $99,80 \mathrm{a}$ & $108,60 \mathrm{~b}$ \\
\hline DMS & 1,97 & 15,77 \\
C.V.\% & 9,1 & 5,78 \\
\hline
\end{tabular}

** $=\mathrm{p}<0,01 ; \mathrm{ns}=$ não significativo; $\mathrm{DMS}=$ diferença mínima significativa; $\mathrm{CV}=$ coeficiente de variação. $\mathrm{S} 1$ : $100 \%$ RCCA (resíduo de carnaúba+casca de arroz); S2: $75 \%$ de RCCA + $25 \%$ de resíduo de carnaúba em pó (RCP); S3: $50 \%$ RCCA + $50 \%$ RCP; S4: $25 \%$ RCCA + $75 \%$ RCP; e 5) RCP.

Quanto ao índice de velocidade de emergência (IVE), não houve diferença estatística entre os tratamentos $\mathrm{S} 1, \mathrm{~S} 2, \mathrm{~S} 3$ e $\mathrm{S} 4$, porém estes foram significativamente superiores ao substrato S5 (Tabela 2), o qual era composto apenas por RCP. De acordo com a análise física desse substrato (S5), observa-se $20 \%$ de espaço de aeração (EA), enquanto o RCCA apresentou $48 \%$ (Tabela 1), o que pode ter contribuído para redução do IVE. Silva-Júnior et al. (2014) ao avaliarem diferentes substratos para a produção de mudas de tomateiro, também obtiveram menores valores de IVE ao utilizarem o substrato RCP. Estes autores correlacionaram estes menores valores ao menor espaço de aeração conferido por este material. Embora tenha ocorrido esta redução estatisticamente significativa para RCP, os valores de IVE, para todos os substratos avaliados são superiores aos encontrados por Souza et al. (2014) para melancia, com valores de IVE variando entre 3,76 a 4,46 ao utilizarem substratos orgânicos. Ainda de acordo com estes autores, o aumento da velocidade de emergência de plântulas pode ser resultado da interação do potencial fisiológico das sementes com as condições benéficas proporcionadas pelo substrato.

As maiores médias de altura de plântula (AP) (Tabela 3) foram encontradas no substrato S1 (RCCA) e S3 (50 \% RCCA + 50 \% RCP). Esses resultados são diferentes dos obtidos por Lopes et al. (2013), ao avaliarem mudas de melancia produzidas em substratos comerciais e registraram $6,94 \mathrm{~cm}$ para plântulas produzidas em fibra de coco, portanto bastante inferior a qualquer tratamento do presente estudo. Souza et al. (2014) obtiveram altura de plântulas de melancia produzidas em substratos orgânicos, inferiores aos do presente trabalho, com médias variando de 5,2 à $6,62 \mathrm{~cm}$, aos 22 DAS.

Cultura Agronômica, Ilha Solteira, v.26, n.1, p.10-20, 2017 
Tabela 3. Altura de plantas (ALT), número de folhas (NF), diâmetro do caule (DC), área foliar (AF), comprimento da maior raiz (CMR), volume radicular (VR), estabilidade do torrão (ET), massa seca da parte aérea (MSPA), massa seca da raiz (MSR), de mudas de melancia cultivadas em diferentes materiais alternativos utilizados como substratos

\begin{tabular}{|c|c|c|c|c|c|c|c|c|}
\hline Causa & ALT & $\mathrm{DC}$ & AF & CMR & VR & ET & MSPA & MSR \\
\hline variação & $\mathrm{cm}$ & $\mathrm{mm}$ & $\mathrm{cm}^{2}$ & $\mathrm{~cm}$ & $\mathrm{~cm}^{3}$ & nota & \multicolumn{2}{|c|}{$-\mathrm{g} \mathrm{planta}^{-1}$} \\
\hline Substrato ("F") & $60,05 * *$ & $\begin{array}{l}17,63 * \\
*\end{array}$ & $78,12 * *$ & $8,36 * *$ & $3,93 * *$ & $\begin{array}{l}1,00^{\mathrm{n}} \\
\mathrm{s}\end{array}$ & $13,35 * *$ & $5,10^{* *}$ \\
\hline $\mathrm{S} 1$ & $16,06 a$ & $2,71 \mathrm{ab}$ & $29,30 \mathrm{a}$ & $8,74 a b$ & $0,07 \mathrm{a}$ & $3,00 \mathrm{a}$ & $0,13 \mathrm{a}$ & $0,02 \mathrm{a}$ \\
\hline $\mathrm{S} 2$ & $12,12 b$ & $2,50 \mathrm{bc}$ & $17,05 \mathrm{c}$ & $7,27 \mathrm{c}$ & $0,06 a b$ & $3,00 \mathrm{a}$ & $0,10 \mathrm{a}$ & $0,02 \mathrm{ab}$ \\
\hline S3 & $14,54 \mathrm{a}$ & $2,81 \mathrm{a}$ & $21,94 b$ & $7,88 \mathrm{bc}$ & $0,06 \mathrm{ab}$ & $3,00 \mathrm{a}$ & $0,12 \mathrm{a}$ & $0,01 b$ \\
\hline S4 & $10,03 c$ & $2,29 \mathrm{~cd}$ & $9,92 d$ & $9,21 \mathrm{a}$ & $0,06 a b$ & $2,97 \mathrm{a}$ & $0,06 \mathrm{~b}$ & $0,01 b$ \\
\hline S5 & $9,83 \mathrm{c}$ & $2,22 \mathrm{~d}$ & $8,55 \mathrm{~d}$ & $8,72 \mathrm{ab}$ & $0,05 b$ & $3,00 \mathrm{a}$ & $0,06 b$ & $0,01 b$ \\
\hline DMS & 1,54 & 0,26 & 4,25 & 1,17 & 0,02 & 0,04 & 0,03 & 0,01 \\
\hline $\mathrm{CV} \%$ & 5,67 & 4,84 & 11,23 & 6,41 & 17,19 & 0,75 & 17,06 & 23,54 \\
\hline
\end{tabular}

** $=\mathrm{p}<0,01 ; \mathrm{ns}=$ não significativo; DMS = diferença mínima significativa; $\mathrm{CV}=$ coeficiente de variação. S1: $100 \%$ RCCA (resíduo de carnaúba+casca de arroz); S2: $75 \%$ de RCCA + $25 \%$ de resíduo de carnaúba em pó (RCP); S3: 50 \% RCCA + 50 \% RCP; S4: $25 \%$ RCCA + $75 \%$ RCP; e 5) RCP.

Para o diâmetro do caule houve superioridade estatística do S1 em relação aos demais substratos, exceto sobre o S3. Comparativamente à literatura é possível inferir que as médias referentes ao substrato S1 são semelhantes às registradas por Souza et al. (2014) ao avaliar a produção de mudas de melancia em substratos orgânicos tendo como base principal o esterco de ovinos. A superioridade do tratamento composto exclusivamente por RCCA foi também observada por Silva-Júnior et al. (2014) em estudo realizado para a cultura do tomateiro.

A área foliar do substrato $\mathrm{S} 1$ foi significativamente superior em relação aos demais tratamentos (Tabela 3). De acordo com Favarin et al. (2002) a área foliar é uma variável indicativa de expansão e divisão celular do vegetal, uma vez que a fotossíntese realizada pelas plantas depende da interceptação da energia luminosa pelo dossel e da sua conversão em energia química. Observa-se que as mudas formadas no substrato S1 apresentaram área foliar quase $70 \%$ superior àquelas mudas produzidas no substrato com o menor desempenho (S5), resultado que pode ser atribuído especialmente às características físicas do S1 (Tabela 1), que é composto apenas por RCCA, pois se analisando os principais constituintes dos substratos (Tabela 1), observa-se que o RCP apresenta maiores teores de nutrientes, em especial N, que poderia ser um indicador para melhores resultados para as características das folhas.

As variáveis de sistema radicular também foram significativamente influenciadas pelo uso de resíduo industrial de carnaúba na composição o substrato.

O comprimento médio de raiz $(\mathrm{CMR})$ foi estatisticamente superior nas mudas produzidas no substrato S4 (25\% RCCA + $75 \% \mathrm{RCP})$ que possui, a menor proporção de

Cultura Agronômica, Ilha Solteira, v.26, n.1, p.10-20, 2017 
RCCA e a segunda maior de RCP, no entanto, com valores semelhantes estatisticamente ao S1 e S5. O RCP, conforme consta na Tabela 1, apresentou a maior quantidade de nutrientes em relação o RCCA, inclusive de fósforo, um nutriente reconhecidamente importante no crescimento radicular, conforme reportado por Grant et al. (2001) em um relato sobre a importância do fósforo no desenvolvimento inicial das plantas. Provavelmente a quantidade de P presente no constituinte RCP foi suficiente para estimular o crescimento das raízes nos substratos com a maior proporção deste material, por outro lado, para RCCA, talvez o efeito maior tenha sido em virtude das características físicas. Grant et al. (2001) reportam que para desenvolvimento das raízes secundárias na cultura do trigo, há necessidade da planta em ter o P disponível no início do crescimento para permitir desenvolvimento máximo das raízes. Comparando-se os resultados contidos na Tabela 2 com outros trabalhos, observa-se que são superiores aos encontrados por Ferreira et al. (2014), que trabalharam com mudas de melancia cv. Crimson Sweet, em casa de vegetação e obtiveram média de $5,51 \mathrm{~cm}$ utilizando como substrato o Plantmax HT ${ }^{\circledR}$; e também aos valores obtidos por Souza et al. (2014), para melancia, com médias entre 5,17 e 6,64 cm em diferentes substratos orgânicos.

O volume radicular (VR), massa seca da parte aérea (MSPA) e massa seca de raiz (MSR) apresentaram tendências semelhantes (Tabela 2) Para o VR, as maiores médias foram registradas para o substrato $\mathrm{S} 1$, sem diferir estatisticamente de S2, S3 e S4, enquanto o S5, composto somente de RCP, promoveu os menores valores (Tabela 3). O volume radicular médio observado para o substrato S1 é compatível ao registrado por Matos et al. (2012) também em estudo com mudas de melancia cv. Crimson Sweet, semeadas em recipientes com $50 \mathrm{~cm}^{3} \mathrm{em}$ casa de vegetação com $50 \%$ de luminosidade. Em relação à MSPA e MSR, os substratos S1 e S2 apresentaram semelhança estatística entre si, sendo estes superiores às demais composições de substratos (S3, S4 e S5). Em trabalho de Souza et al. (2014), os resultados não foram muito diferentes na produção de mudas de melancia, os quais obtiveram médias entre 0,09 à $0,112 \mathrm{~g} \mathrm{plnata}^{-1}$ de MSPA e 0,032 e 0,052 $\mathrm{g} \mathrm{planta}^{-1}$ de MSR. As semelhanças nas tendências dos resultados entre essas variáveis indicam que o desenvolvimento radicular no S1 apresentou maior crescimento lateral em relação à profundidade proporcionando melhor sustentação à planta e acesso à água e nutrientes essenciais, conforme Rejano et al. (2011) observaram em Arabidopsis, relatando sobre a importância da boa formação da arquitetura radicular para o desenvolvimento e crescimento de uma boa muda, com biomassa maior.

Para a variável estabilidade do torrão (ET) não houve diferença estatística entre os tratamentos avaliados (Tabela 3), ou seja, ao retirar a planta do recipiente, o substrato permaneceu aderido à raiz da planta, o que proporcionou a sustentação da planta e permitiu desenvolvimento normal. Esta coesão do substrato é desejável, pois evita que a muda, em especial o sistema radicular, sofra estresses ao ser transplantada para a área definitiva. De acordo com Souza et al. (2013), a formação de raízes maiores permite às plântulas explorarem melhor o volume de substrato disponibilizado, possibilitando maior absorção de água e nutrientes, além de evitar a fragmentação do torrão durante o transplante.

Cultura Agronômica, Ilha Solteira, v.26, n.1, p.10-20, 2017 
Em suma, observou-se que, pelas características químicas dos substratos estudados, o constituinte RCP apresentou uma quantidade maior de nutrientes (Tabela 1), no entanto, por outro lado, o RCCA apresentou características físicas mais favoráveis ao desenvolvimento das mudas. De acordo com Milner (2006), as propriedades físicas são essenciais para um substrato com qualidade e não podem ser facilmente mudadas como as propriedades químicas por meio da irrigação, adubação e/ou fertirrigação.

\section{CONCLUSÃO}

O uso do resíduo da indústria de cera de carnaúba como componente de substrato constitui-se em uma alternativa viável para produção de mudas de melancia.

O substrato S1 constituído de $100 \%$ de resíduo de carnaúba com casca de arroz (RCCA) é indicado para produção de mudas de melancia.

\section{REFERÊNCIAS BIBLIOGRÁFICAS}

ALBANO, F. G.; MARQUES, A. S.; CAVALCANTE, I. H. L. Substrato alternativo para produção de mamoeiro formosa (cv. Caliman). Científica, Jaboticabal, v. 42, n. 4, p.388-395, 2014.

BASSO, S. M. S. Morphological and biological nitrogen fixation of Adesmia DC. $E$. Lotus L. 1999. 268 f. Tese (Doutorado em Agronomia) - Universidade Federal do Rio Grande do Sul, Porto Alegre, 1999.

CAVAlCANTE, M. Z. B. Características de substratos e concentrações de soluções nutritivas para o cultivo de crisântemo em vaso. 2007. 145 f. Tese (Doutorado em Agronomia - Produção Vegetal) - Faculdade de Ciências Agrárias e Veterinárias, Universidade Estadual Paulista, Jaboticabal, 2007.

CAVAlCANTE, M. Z. B.; AMARAL, G. C.; SILVA, A. A.; CAVAlCANTE, I. H. L.; LIMA, M. P. D. Alternative substrates for production of Heliconiapsittacorum L. seedlings under shade and open field conditions. African Journal of Biotechnology, Nairobi, v. 10, n. 88, p.15272-15277, 2011.

FAVARIN, J. L.; NETO, D. D.; GARCIA, A.; VILlA NOVA, N. A.; FAVARIN, M. G. G. V. E. Equações para a estimativa do índice de área foliar do cafeeiro. Pesquisa Agropecuária Brasileira, Brasília, v. 37, n. 6, p.769-773, 2002.

FERREIRA, L. G.; SILVA, L. R.; MONDIN, M.; NESSI JUNIOR, P. Bandejas e substratos na produção de mudas de melancia. Enciclopédia Biosfera, Goiânia, v. 10, n. 19, p.407-413, 2014.

GONÇALVES, J. L. M.; BENEDETTI, V. Forest nutrition and fertilization. Piracicaba: IPEF, 2004. $421 \mathrm{p}$.

Cultura Agronômica, Ilha Solteira, v.26, n.1, p.10-20, 2017 
GRANT, C.A.; FLATEN, D.N.; TOMASIEWICZ, D.J.; SHEPPARD, S.C. A importância do fósforo no desenvolvimento inicial da planta. Informações Agronômicas, Piracicaba, n. 95, p.1-5, 2001.

GRUSZYNSKI, C. Resíduo agroindustrial: casca de tungue como componente de substrato para plantas. 2002. 41 f. Dissertação (Mestrado em Agronomia) - Universidade Federal do Rio Grande do Sul, Porto Alegre, 2002.

IBGE. Instituto Brasileiro de Geografia e Estatística. Levantamento sistemático da produção agrícola. 2015. Disponível em: http://www.ibge.gov.br/. Acesso em: 11 abr. 2016.

LOPES, H. S.; CASTILHO, R. M. M.; LOPES, H. S. Germinação e crescimento inicial de plântulas de melancia em diferentes substratos comerciais. Revista Tecnologia \& Ciência Agropecuária, João Pessoa, v. 7, n. 4, p.25-29, 2013.

LUSTOSA FILHO, J. F.; NÓBREGA, J. C. A.; NÓBREGA, R. S. A.; DIAS, B. O.; AMARAL, F. H. C.; AMORIM, S. P. N. Influence of organic substrates on growth and nutrient contents of jatobá (Hymenaea stigonocarpa). African Journal of Agricultural Research, Nairobi, v. 10, n. 26, p.2544-2552, 2015.

MAGUIRE, J. D. Speed of germination aid in selection aid evolution for seedling emergence and vigor. Crop Science, Madison, v. 2, p.176-177, 1962.

MALAVOLTA, E.; VITTI, G. C.; OLIVEIRA, S. A. Avaliação do estado nutricional das plantas: princípios e aplicações. 2. ed. Piracicaba: Potafos, 1997. 319 p.

MAPA. Instrução Normativa n. 17, de 21 de Maio 2007. Diário Oficial da República Federativa do Brasil, Brasília, p. 8. seção 1, 2007. (Boletim Técnico, 17).

MATOS, R. R. S.; CAVALCANTE, I. H. L.; JUNIOR, G. B. S.; ALBANO, F. G.; CUNHA, M. S.; BECKMANN-CAVALCANTE, M. Z. Foliar spray of humic substances on seedling production of watermelon cv. Crimson Sweet. Journal of Agronomy, New York, v. 11, n. 2, p.60-64, 2012.

MILNER, L. Manejo da irrigação e fertirrigação em substratos: aspectos práticos. In: ENCONTRO BRASILEIRO SOBRE SUBSTRATOS PARA PLANTAS, 5., 2006, Ilhéus. Anais... Ilhéus: CEPLAC/CEPEC, 2006. p. 13-17.

OLIVEIRA, M. K. T.; OLIVEIRA, F. A.; MEDEIROS, J. F.; LIMA, C. J. G. S.; GALVÃO, D. C. Avaliação de substratos orgânicos na produção de mudas de berinjela e pimenta. Revista Verde, Mossoró, v. 1, n. 2, p.24-32, 2006.

REJANO, E. M.; CAMACHO-CRISTÓBAL, J. J.; HERRERA-RODRIGUEZ REXACH, J.; NAVARRO-GOCHICOA, M. T.; GONZALEZ FONTES, A. Auxin and ethylene are involved in the responses of root system architecture to low boron supply in Arabidopsis seedlings. Physiologia Plantarum, Sweden, v. 142, n. 2, p. 170-178, 2011.

SILVA-JÚNIOR, J. V.; CAVALCANTE, M. Z. B.; BRITO, L. P. S.; AVELINO, R. C.; CAVALCANTE, I. H. L. Aproveitamento de materiais regionais na produção de mudas de 
tomateiro sob adubação foliar. Revista Ciência Agronômica, Fortaleza, v. 45, n. 3, p.528536, 2014.

SOUSA, L. B.; LUSTOSA FILHO, J. F.; AMORIM, S. P. N.; NÓBREGA, R. S. A.; NÓBREGA, J. C. A. Germinação, crescimento e nodulação natural de Enterolobium contortisiliquumem substratos regionais. Revista Brasileira de Agroecologia, Rio de Janeiro, v. 11, n. 4, p.345-353, 2016.

SOUZA, E. G. F.; BARROS JÚNIOR, A. P.; SILVEIRA, L. M.; CALADO, T. B.; SOBREIRA, A. M. Produção de mudas de alface Babá de Verão com substratos à base de esterco ovino. Revista Caatinga, Mossoró, v. 26, n. 4, p.63-68, 2013.

SOUZA, E. G. F.; SANTANA, F. M. S.; MARTINS, B. N. M.; PEREIRA, D. L.; BARROS JÚNIOR, A. P.; SILVEIRA, L. M. Produção de mudas de cucurbitáceas utilizando esterco ovino na composição de substratos orgânicos. Revista Agro@mbiente, Boa Vista, v. 8, n. 2, p.175-183, 2014. 